\title{
BIM and Post-occupancy Evaluations for Building Management System: Weaknesses and Opportunities
}

\author{
Giuseppe Martino Di Giuda, Laura Pellegrini, Marco Schievano, \\ Mirko Locatelli and Francesco Paleari
}

\begin{abstract}
The goal of this work is to provide a state of the art about POE fields of use, opportunities, weaknesses and tools, which is currently used to perform POE combined with BIM methodology. The application of POE on existing buildings can provide a large amount of data on actual uses, supply needs and users' behaviour: the main aspect is to explore the potential application of IoT sensors and Machine Learning techniques to POE.
\end{abstract}

Keywords Post-occupancy evaluation $\cdot$ Digitalization $\cdot$ Performances optimization $\cdot$ Operational phase $\cdot$ IoT sensors $\cdot$ Machine learning

\section{Introduction}

Several analyses carried out since the 1990s established a ratio of 1:5:200 over the life of a 30-year-old office building, in relation to construction, maintenance and operating costs respectively (Wu and Clements-Croome 2007; Evans et al. 1998): costs associated with the operational phase have a significant impact on the total cost of the building life cycle. It is necessary to optimize the process of building management in this phase to ensure functionality and efficiency. Actual uses of spaces, supply needs and users' behaviour have strong impacts on functionality and consumptions (Bento Pereira et al. 2016; Zimmerman and Martin 2001) and can cause higher consumptions of energy, space or resources. This, in turn, can result in additional costs or lower quality of available services and, in any case, in lower satisfaction of users. Despite its importance to optimize building performances and consumptions, users' feedback is not even investigated (Royal Institute of British Architects (RIBA) 1965; Cooper 2001). Unless these aspects are managed during the operational phase, it is hard being aware of possible issues in terms of quality or higher costs.

G. M. Di Giuda ( $\varangle) \cdot$ L. Pellegrini · M. Schievano $~ M$ M. Locatelli · F. Paleari Architecture, Built Environment and Construction Engineering-ABC Department,

Politecnico di Milano, Milan, Italy

e-mail: giuseppe.digiuda@polimi.it

B. Daniotti et al. (eds.), Digital Transformation of the Design, Construction and Management Processes of the Built Environment, Research for Development, https://doi.org/10.1007/978-3-030-33570-0_29 
In this context, post-occupancy evaluations (POEs) can lead to an improvement in the above issues. POEs, that are also called 'building-in-use-studies' (Preiser 2010), were defined by RIBA as systematic studies 'of buildings in use to provide architects with information about the performance of their designs, and building owners and users with guidelines to achieve the best out of what they already have' (Royal Institute of British Architects (RIBA) R.S.G. 1991). POEs can provide predictive data to improve buildings' use and management (Leaman et al. 2010).

First applications of POEs started in the 1960s, but the main development of POEs' theory and strategy has been carried out since the 1980s, as a tool for facility management and design phases.

This work provides a state of the art about POEs, including POE's opportunities and weaknesses, an overview of subjects involved and a resume of available tools to perform POEs. A systematic approach was adopted to review related publications and research gaps and further developments are finally presented.

\section{Opportunities}

POEs can improve the management of existing buildings and the design of new ones, providing more efficiency and user satisfaction. POEs benefits are shown in the following flow (Fig. 1).

Moving from short-term benefits to medium- and long-term ones, the effort required increases, but the effects are spread from the operational phase to the whole life cycle. Benefits and drivers provided by POEs are reviewed in Table 1.

Drivers show the usefulness of POEs to improve existing and future buildings. They could provide savings in terms of resources, costs, and time, as well as increased user satisfaction. Referring to feedback for the design process, however, it may take a long time to obtain valid and consistent data to define databases. Increasing user satisfaction can even be a hard result to achieve with very fast user turnover. In addition, there are some weaknesses relating to POEs highlighting several limits to the spread of this kind of analyses that are presented in the following paragraph.
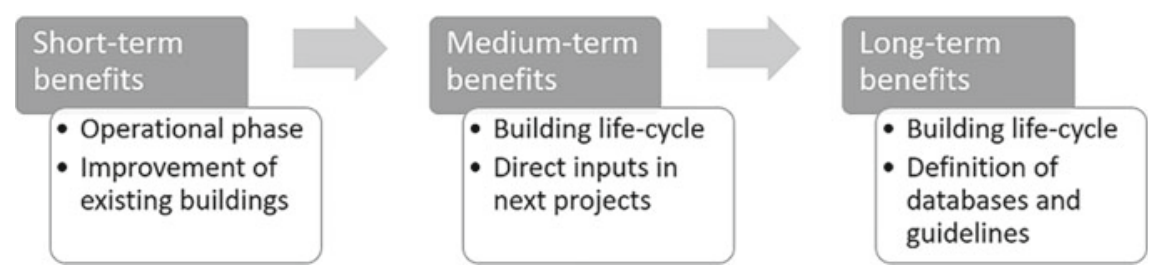

Fig. 1 Definition of short-, medium- and long-term benefits of POEs (Preiser 2010 adjusted) 
Table 1 Opportunities of POEs

\begin{tabular}{l|l} 
Continuous improvement & $\begin{array}{l}\text { The large amount of data of actual uses can provide } \\
\text { valuable information for continuous improvement of } \\
\text { building operational stage, the short-term benefit of } \\
\text { POEs (Zimmerman and Martin 2001; Preiser 2010) }\end{array}$
\end{tabular}

Analyses can provide predictive information (Leaman et al. 2010) for building operational phase in order to define accurate and specific management plans

\begin{tabular}{l|l}
\hline Increased users' satisfaction & POEs help to determine whether the initial conditions
\end{tabular} ensure comfort and user satisfaction in the operational phase, and results can be used to both rectify weaknesses and inform next projects (medium-term benefits of POE application (Preiser 2010))

Feedback for design process

POEs allow to improve future designs, removing or modifying spaces that are not producing the expected function in existing facilities, according to actual needs (Zimmerman and Martin 2001). As a result, user satisfaction and building efficiency would increase

POEs collect robust data on usage patterns (Leaman et al. 2010) producing valid, reproducible and generalizable results, leading to the definition of design criteria and guidelines relating to the building function and type of users (long-term benefits of POE application (Preiser 2010; National Research Council 1987))

\begin{tabular}{l|l}
\hline Reduction of energy consumption & POEs help defining whether the building's
\end{tabular} performance is negative or positive

The influence of users' effective behaviour on usage patterns and consumptions of the building can be defined (Straka and Aleksic 2009)

Benchmarks and standards are available for energy performance and indoor air quality monitoring, resulting in easier data analyses and evaluation

Reduction of operational phase's costs

Lower need for adjustments once buildings are occupied results in lower costs

Efficient use of buildings, i.e. limiting heating, cooling, resource use, cleaning activities and spaces management only to occupied areas and during operating hours, can optimize consumptions and lead to cost savings 


\section{Weaknesses}

Traditionally, POEs are not part of the standard in common practice, despite the advantages introduced in the previous section. Some obstacles to the dissemination of POEs are investigated as follows (Table 2).

The barriers stated above involve most of the actors of the building design and management process, limiting the application of this type of analysis.

The lack of awareness of the main goal and benchmarks, on one hand, causes the collection of useless data or to over/low-detailed analyses. The result is the increasing of costs and complexity of POEs. The lack of indicators referring user's needs, on the other hand, precludes the definition of whether POEs show positive or negative results.

Table 2 Barriers to POEs

\begin{tabular}{l|l}
\hline Standard practice & $\begin{array}{l}\text { There is institutionalized pressure in AEC industry to carry on with } \\
\text { standard practice and not to innovate, to avoid any delay in financing, } \\
\text { approvals or design processes (Lovins 1992) }\end{array}$ \\
\cline { 2 - 3 } Benchmarks & $\begin{array}{l}\text { AEC industry specialists are neither interested in actual usage patterns } \\
\text { nor in the analyses of building performances and weaknesses, once } \\
\text { occupied (Leaman et al. 2010) }\end{array}$ \\
& $\begin{array}{l}\text { Users' needs depend on their age, features, occupation, etc. (Bento } \\
\text { Pereira et al. 2016) resulting in their difficult definition }\end{array}$ \\
\hline $\begin{array}{l}\text { Each building specialist taking part in the building life cycle has its } \\
\text { own targets, performance requirements, outlook, technical language } \\
\text { and incentives to achieve their goals. Clients, in turn, are placing } \\
\text { ever-increasing demands on buildings (Preiser 2010). Besides this, in } \\
\text { many cases clients' and specialists' requirements are different from } \\
\text { users' needs (Zimmerman and Martin 2001). This fragmentation of the } \\
\text { AEC industry and lack of shared goals results in huge efforts to define } \\
\text { benchmarks }\end{array}$ & $\begin{array}{l}\text { Thresholds should even be defined in relation to each type of building, } \\
\text { whether residential, service or commercial buildings }\end{array}$ \\
\hline Liability & $\begin{array}{l}\text { POEs can highlight current issues of existing buildings: low user } \\
\text { satisfaction, usage patterns producing waste of energy and resources, } \\
\text { poor indoor environmental conditions and inefficient energy } \\
\text { performances. Liabilities resulting from an awareness of the real } \\
\text { conditions of buildings create resistance of AEC industry in the use of } \\
\text { POEs (Zimmerman and Martin 2001; Leaman et al. 2010) }\end{array}$ \\
\hline Implementation costs & $\begin{array}{l}\text { POE performing appears as a discomfort and a restriction on user } \\
\text { privacy } \\
\text { Users are reluctant to take part in this kind of analyses as a result of the } \\
\text { effort required } \\
\text { especially to large buildings }\end{array}$ \\
\hline High levels of details in the analyses cause even increased costs \\
\hline Users' reluctance
\end{tabular}


Referring to liability, several rented out building owners will be reluctant to carry out analyses such as a POEs that could reveal weaknesses of their building compared to similar ones. As a result, Zimmerman and Martin pointed out that tenants would move out, producing a reduction in revenue. They define this mentality as 'ignorance is bliss' (Zimmerman and Martin 2001): building managers and owners reject innovative methods that generate better or more complete information, since they can result in lower profits.

It is clear that costs of application are a further obstacle to the spread of POEs and, as mentioned above, researchers should consider a level of detail according to the criticism detected with a basic survey. This avoids collecting unnecessary and oversized data on lower critical areas or topics. Indeed, the lower the costs and the shorter the application time, the better. This, in turn, can increase the cooperation of users and occupiers and may limit users' opposition to carrying out the analyses.

\section{Actors Involved}

Once drivers and obstacles to POEs were discussed, positive and negative aspects related to the actors involved in the design and management process were investigated. Each AEC industry specialist and stakeholder has its own goals to achieve, as well as targets in terms of building performance and negative impacts to avoid, as shown below (Table 3).

The observed aspects point out the need for attention in carrying out this kind of analysis considering the possible negative consequences on the different actors involved.

\section{Tools and Levels of POEs}

Users' reluctance towards POEs, one of the barriers outlined above, has a strong impact on the selection of how a POE is performed. In this sense, the three levels of detail of POEs are defined (Preiser 2010) as

- Indicative POEs;

- Investigative POEs;

- Diagnostic POEs.

The more in-depth and invasive the analyses are, the more reluctant users will be (Fig. 2).

Indicative POEs can be indeed used for an overall analysis of the building to identify the main issues. The aim is the identification of the most critical areas and aspects, which are therefore object of more in-depth analyses. Observations, on-site photographic surveys and interviews are used in indicative POEs; they are 
Table 3 Actors involved and pros-cons of POEs

\begin{tabular}{|c|c|c|}
\hline Actor & Pros & Cons \\
\hline Facility owner & $\begin{array}{l}\text { Better end product creates value } \\
\text { for money invested (Meir et al. } \\
2009 \text { ) }\end{array}$ & $\begin{array}{l}\text { Overemphasizing on } \\
\text { malfunctioning and hazardous } \\
\text { buildings (Meir et al. 2009) }\end{array}$ \\
\hline Building manager/owner & $\begin{array}{l}\text { Optimization of existing and } \\
\text { future buildings (Leaman et al. } \\
\text { 2010): more efficient buildings, } \\
\text { lower consumptions and } \\
\text { maintenance costs }\end{array}$ & $\begin{array}{l}\text { Overemphasizing on } \\
\text { malfunctioning and hazardous } \\
\text { buildings (Meir et al. 2009) }\end{array}$ \\
\hline \multirow[t]{2}{*}{ Users } & \multirow[t]{2}{*}{$\begin{array}{l}\text { Increasing healthy conditions, } \\
\text { comfort and productivity }\end{array}$} & $\begin{array}{l}\text { Analyses can be invasive such } \\
\text { as interviews }\end{array}$ \\
\hline & & $\begin{array}{l}\text { Hard to provide objective } \\
\text { feedback }\end{array}$ \\
\hline Design teams & $\begin{array}{l}\text { Feedback from previous } \\
\text { occupied facilities can improve } \\
\text { future projects and gain a } \\
\text { competitive edge over other } \\
\text { specialists, resulting in } \\
\text { increased fees/additional work } \\
\text { and better future designs }\end{array}$ & $\begin{array}{l}\text { Reluctance to use POEs since } \\
\text { early planning due to the } \\
\text { complexity of managing large } \\
\text { amounts of data and the need } \\
\text { for coordination between } \\
\text { disciplinary teams }\end{array}$ \\
\hline \multirow[t]{2}{*}{ Institutional stakeholders } & $\begin{array}{l}\text { Promotion of better design and } \\
\text { building practices (Meir et al. } \\
2009 \text { ) }\end{array}$ & \multirow[t]{2}{*}{$\begin{array}{l}\text { Costs of performing POEs } \\
\text { especially in large buildings }\end{array}$} \\
\hline & $\begin{array}{l}\text { Increasing longevity of } \\
\text { buildings minimizing the need } \\
\text { for changes (Meir et al. 2009) }\end{array}$ & \\
\hline
\end{tabular}

Fig. 2 Indicative, investigative and diagnostic POEs

non-invasive and less expensive analysis tools (Preiser 2010), despite they can be inaccurate. Another problem concerns interviews, i.e. subjective feelings expressed by users.

Investigative POEs are more in-depth analyses adding questionnaires, video recordings and local measurements (Preiser 2010). These tools can be invasive referring to user's privacy. Questionnaires show the same problem as interviews, subjectivity, therefore objective indices to evaluate the building performances should be set. 
Diagnostic POEs are detailed analyses involving widespread and continuous monitoring, defining consistent databases (Preiser 2010). Monitoring by means of sensors systems, mostly used to verify building energy consumptions (Marzouk and Abdelaty 2014; Costa et al. 2015; Demian et al. 2018), can provide objective data concerning the building usage pattern. Sensors technologies allow to compare actual use and consumptions with the building performance as obtained through simulations during the design phase (Straka and Aleksic 2009). Design documents' analysis allows to identify discrepancy between the way a building should be used and its actual use defined with the above tools, especially referring to sustainable buildings, whose improper use can be the cause of potential waste. Despite this benefits, diagnostic POEs are invasive, expensive analyses and provide large amounts of data to be analysed.

The application of IoT sensor systems can be useful to collect huge amounts of data, a key aspect to ensure the effectiveness of POE. This is a rapidly expanding technology in many contexts, and is now consolidated with several research and applications in the optimization of energy performances.

An in-depth analysis of several publications (Demian et al. 2018) dealing with the integration between sensors and BIM methodology showed these results: it was identified that a limited number of publications dealt with the use of sensors in the operations and maintenance phase (23\%) and in the tracing of people and facilities $(12 \%)$. It is clear that structured data can be then integrated into the building information model; sensors data, saved in the building model, become valuable to keep information accurate and up to date (Underwood and Isikdag 2011).

Nonetheless, a deep analysis with sensors, besides being limited to critical areas, could involve a huge quantity of data, as a result of the integration of POEs analyses with IoT sensors systems. To date, there is an imbalance between data acquisition and analysis (Ahmed et al. 2017), so it is necessary to define a system for the classification and analysis of large amounts of data. These structured data can be fed to an artificial intelligence based on Machine Learning methods (ANN). This could bring to predictive information for an improvement of building performance and use, that is one of the main goals of POEs.

\section{Conclusions}

The state of the art stated above aims to identify the main obstacles to the dissemination of POEs and to the integration of these analyses into the traditional management and design process. Furthermore, a review of available tools and their negative and positive sides can allow an informed choice of the best approaches to adopt, according to the level of detail needed. The aim should also be to create fewer negative effects on actors.

The research gaps identified can be resumed in the following aspects, underlining potential developments: 
1. Define accurate thresholds and benchmarks to compare collected data.

2. Make owners and managers aware of the considerable savings that result from the application of POEs. At the same time, there is a need to reduce the perceived fear of POEs producing a decrease in profits. Analyses, indeed, may initially highlight shortcomings and problems, but once solutions are identified, increased user satisfaction and predictive information relating to building management during the operational phase can lead to benefits such as

- Improving users' perception of carrying out POEs.

- Increasing users' morale and even productivity at work.

- Cost savings in maintaining and operating facilities, resulting from an efficient use of spaces and resources.

3. Find the best method of carrying out the analyses depending on lower discomfort and limitation of users' privacy. The optimization of the costs of POEs implementation can also be achieved according to desired outcomes and weaknesses detected.

POEs could represent an answer to existing issues, both through questionnaires and interviews to evaluate users' satisfaction, and by means of sensor for environmental condition analysis. This approach could bring to a complete definition of an existing building's conditions. The integration of POEs, IoT sensors technology and Building Information Modelling could result in a better structuring, archiving and continuously updating of data coming from POEs.

Further developments may regard the use of Machine Learning techniques to accurately analyse data and to define predictive information for the operational phase of a building. The application to case studies can lead to the definition of advantages, disadvantages and issues of the outlined method. At the same time, databases from POEs on existing buildings will be used to define guidelines for future buildings implementation.

\section{References}

Ahmed V, Tezel A, Aziz Z, Sibley M (2017) The future of Big Data in facilities management: opportunities and challenges. Facilities 35:725-745

Bento Pereira N, Calejo Rodrigues R, Fernandes Rocha P, Bento Pereira N, Calejo Rodrigues R, Fernandes Rocha $\mathrm{P}$ (2016) Post-occupancy evaluation data support for planning and management of building maintenance plans. Buildings 6:45

Cooper I (2001) Post-occupancy evaluation—where are you? Build Res Inf 29:158-163

Costa AA, Lopes PM, Antunes A, Cabral I, Grilo A, Rodrigues FM (2015) 3I Buildings: intelligent, interactive and immersive buildings. Procedia Eng 123:7-14

Demian P, Liu Z, Deng Z (2018) Integration of Building Information Modelling (BIM) and sensor technology : a review of current developments and future outlooks. In: CSAE

Evans R, Haryott H, Naste N, Jones A (1998) The longterm costs of owning and using buildings. London

Leaman A, Stevenson F, Bordass B (2010) Building evaluation: practice and principles. Build Res Inf 38:564-577 
Lovins A (1992) Energy-efficient buildings: institutional barriers and opportunities. E Source Inc., Boulder, CO (United States)

Marzouk M, Abdelaty A (2014) BIM-based framework for managing performance of subway stations. Autom Constr 41:70-77

Meir IA, Garb Y, Jiao D, Cicelsky A (2009) Post-occupancy evaluation: an inevitable step toward sustainability. Adv Build Energy Res 3:189-220

National Research Council (1987) Post-occupancy evaluation practices in the building process: opportunities for improvement. National Academy Press, Washington, DC

Preiser WFE (2010) Post-occupancy evaluation: how to make buildings work better. Facilities 13:19-28

Royal Institute of British Architects (RIBA) (1965) Handbook of architectural practice and management. RIBA Publications, London

Royal Institute of British Architects (RIBA) R.S.G. (1991) A research report for the architectural profession. In: Duffy F, Hutton L (eds) Architectural knowledge: the idea of a profession. Taylor \& Francis, London

Straka V, Aleksic M (2009) Post-occupancy evaluation. Three schools from Greater Toronto. In: PLEA2009-26th conference passive and low energy architecture 5

Underwood J, Isikdag U (2011) Emerging technologies for BIM 2.0. Constr Innov 11:252-258

Wu S, Clements-Croome D (2007) Ratio of operating and maintenance costs to initial costs of building services systems. Cost Eng 49:30-33

Zimmerman A, Martin M (2001) Post-occupancy evaluation: benefits and barriers. Build Res Inf 29:168-174

Open Access This chapter is licensed under the terms of the Creative Commons Attribution 4.0 International License (http://creativecommons.org/licenses/by/4.0/), which permits use, sharing, adaptation, distribution and reproduction in any medium or format, as long as you give appropriate credit to the original author(s) and the source, provide a link to the Creative Commons license and indicate if changes were made.

The images or other third party material in this chapter are included in the chapter's Creative Commons license, unless indicated otherwise in a credit line to the material. If material is not included in the chapter's Creative Commons license and your intended use is not permitted by statutory regulation or exceeds the permitted use, you will need to obtain permission directly from the copyright holder.

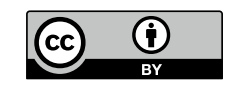

